\title{
Polymorphisms in the Promoters of MMP-1 and TIMP-1 Genes in Patients with
}

\section{Acne Vulgaris}

H. H.Sabry ${ }^{1}$, R.M.ASalem ${ }^{1}$, S.G.Ameen ${ }^{2}$ and S.M.Ali ${ }^{1}$

${ }^{1}$ Dermatology, Venereology and Andrology Dept., Faculty of Medicine, Benha Univ., Benha, Egypt

${ }^{2}$ Clinical Pathology and Immunology Dept., Faculty of Medicine, Benha Univ., Benha, Egypt

\section{E-Mail: Ahmed_ramadanzaid@yahoo.com}

\begin{abstract}
Grid metalloproteinases (MMPs) and their particular inhibitors (tissue inhibitors of metalloproteinases, TIMPs) are fundamental for the redesigning of the extracellular framework, and incendiary infections, for example, skin inflammation. Skin break out vulgaris is an incessant incendiary illness that influences most of the populace. It is described by comedones, pustules, and papules. In this examination, it was expected to research the possible relationship between MMP-1 quality polymorphism and the hazard for skin inflammation advancement. Polymorphism of MMP-1 Gene was estimated in 60 patients with skin break out vulgaris and 40 solid controls utilizing polymerase chain response (PCR). A noteworthy connection between MMP-1 (1607 $\mathrm{A} / \mathrm{G})$ polymorphism and skin inflammation vulgaris was recognized.
\end{abstract}

Keywords: Acne vulgaris, MMP-1, Gene polymorphism.

\section{Introduction}

Grid metalloproteinases (MMPs) are the significant protein family liable for extracellular lattice (ECM) renovating and, all things considered, they can cut all ECM segments by sharing regular substrates. Generally, the organic job of MMPs has been connected uniquely with ECM debasement and turnover [1]. Qualities encoding collagen-debasing proteins-lattice metalloproteinase type 1 (collagenase-1) and network metalloproteinase type 3 (stromelysin) are situated on the long arm of chromosome 11. SNP because of the inclusion of the additional guanine (G) base at position $-1607 /-1608$ upstream from the beginning of interpretation upregulates MMP-1 translation and conceivably expands the tissue action of network metalloproteinase type 1 chemical [2].

Skin inflammation vulgaris is a constant, fiery malady of the sebaceous follicles portrayed by expanded sebum discharge and development of follicle-related shut and open comedones, papules, pustules and knobs; pseudocysts and a few sorts of scars as a sequelae of the essential sores [1].

There are four significant pathogenetic factors that have been involved in skin break out pathogenesis, in particular sebaceous organ hyperplasia with seborrhea, changed follicular development and separation, Propionibacterium acnes (P. acnes) colonization of the pilosebaceous unit, and aggravation [3].

Numerous incendiary middle people assume job in etiopathogenesis of skin break out vulgaris, particularly framework metalloproteinases. They can pulverize basal film proteins and ECM components. In the skin, MMPs can be delivered by a wide range of cells, including fibroblasts, macrophages, keratinocytes, $\mathrm{T}$ cells, endothelial cells, and pole cells. Tissue inhibitors of metalloproteinases (TIMPs) manage MMP action, and the harmony among MMPs and TIMPs directs the renovating of ECM. When MMPs and TIMPs are out of parity, incendiary ailments, for example, skin break out can happen [4].

The point of this examination was to assess the relationship between MMP-1 (1607 A/G) quality polymorphism and hazard to create skin inflammation vulgaris.

\section{Patients and methods}

This is a cross Section case control study .The study included sixty patients with acne vulgaris and forty healthy subjects, age and sex matched, attending the dermatology outpatient clinic at Benha University Hospital, Benha, Egypt from May 2019 to May 2020.

Participants gave their informed written consent before enrollment and the study was approved by the Research Ethics Committee in Faculty of Medicine, Benha University.

All patients included in the study have moderate to severe recurrent acne lesions, acne scar and aged from 11 to 30 years old. Patients with Acniform eruption, Acne conglobate and Fulminating acne were excluded.

\subsection{Laboratory investigations}

A) Two millimiters of venous blood tests pulled back from every member in the investigation into an EDTA (Ethylene Diamine Tetra-Acetic salt) tubes under complete aseptic conditions, blood was put away at $-20^{\circ}$ until dissected.

B) DNA extraction and genotyping were done from EDTA entire blood.

DNA extraction from fringe entire blood by utilizing snappy - DNA TM miniprep pack inventory Nos D3006, D3007, D3024 and D3025. As per maker's convention.

\subsection{Statistical analysis}

Measurable investigation was performed utilizing the Statistical Package for Social Sciences 
(SPSS) vs.25. Mean \pm SD, Tukey test, Chi square test, Fisher's careful test, Regression examination and Deviations from Hardy-Weinberg harmony were utilized.

MMP1 (1607 A/G) alleles and genotypes in the studied groups.
The MMP1 (1607 A/G) AG and GG genotypes and $\mathrm{G}$ alleles increase the risk of acne vulgaris $2-3$ folds Table (1).

\section{Results}

Table (1) MMP1 (1607 A/G) alleles and genotypes in the studied groups.

\begin{tabular}{|c|c|c|c|c|c|c|}
\hline & & $\begin{array}{l}\text { Patients } \\
(\text { No.=60) }\end{array}$ & $\begin{array}{l}\text { Controls } \\
(\text { No.=40) }\end{array}$ & P-value & $\overline{\text { OR }}$ & $95 \% \mathrm{CI}$ \\
\hline \multirow{5}{*}{$\begin{array}{l}\text { MMP1 } \\
(1607 \text { A/G) }\end{array}$} & & $\mathrm{N}(\%)$ & $\mathrm{N}(\%)$ & & & \multirow[b]{2}{*}{ Reference } \\
\hline & $\mathrm{A} / \mathrm{A}$ & $24(40)$ & $28(70)$ & \multirow{3}{*}{0.003} & 1 & \\
\hline & $(\mathrm{A} / \mathrm{G})+(\mathrm{G} / \mathrm{G})$ & $36(60.0)$ & $12(30.0)$ & & 2.162 & 1.292 \\
\hline & A & $70(58.3)$ & $65(81.3)$ & & 1 & Reference \\
\hline & $\mathrm{G}$ & $50(41.7)$ & $15(18.8)$ & 0.001 & 3.095 & 1.586 \\
\hline
\end{tabular}

$\mathrm{R}$, reference; OR, odds ratio; CI, confidence interval. Logistic regression test was used.

\section{Discussion}

Skin inflammation is a multifactorial infection that is at first determined by androgen incited expanded sebum overproduction, adjusted and strange keratinization, irritation, bacterial colonization of pilosebaceous unit on the face by Propionibacterium acnes (P. acnes), postponed type invulnerable reaction, outer components and hereditary qualities [5].

Network metalloproteinases (MMPs) are a group of proteolytic catalysts that manage extracellular grid (ECM) turnover and provocative flagging. Actuated MMPs are firmly directed by endogenous tissue inhibitor of metalloproteinases (TIMPs), which additionally apply their impacts on cell expansion, separation, apoptosis, and angiogenesis by MMP-free instruments [6].

Network metalloproteinases (MMPs) and tissue inhibitors of metalloproteinases (TIMPs) assume basic jobs in the provocative procedure and grid renovating after aggravation [7].

In this investigation, a huge connection between MMP-1 (1607 A/G) polymorphism and skin inflammation vulgaris was distinguished. The frequencies of MMP-1 (1607 A/G) genotypes and alleles were distinctive in skin break out patients and control gatherings. AG and GG genotypes and $\mathrm{G}$ allele appear to build the hazard to create skin break out 2-3 folds of alleles in patients and control subjects.

A similar SNP was concentrated in polycystic ovary patients. They identified a relationship between the danger of polycystic ovary and GG genotype of MMP1. Polycystic ovary is related with various skin indications identified with hormonal changes including skin inflammation vulgaris [8]. The current discoveries along with [9] results propose a hereditary foundation to this affiliation.

\section{Conclusion}

MMP-1 (1607 A/G) quality polymorphism is related with the powerlessness of advancement of skin inflammation among the considered gathering of Egyptian populace.

\section{I-Financial support and sponsorship}

Nil.

\section{II-Conflicts of interest}

There are no conflicts of interest.

\section{Reference}

[1] P. Pittayapruek, J. Meephansan, O. Prapapan. Role of matrix metalloproteinases in photoaging and photocarcinogenesis. International journal of molecular sciences ,Vol.17(6), pp.868, 2016.

[2] B. Grünwald, B. Schoeps, A. Krüger. Recognizing the molecular multifunctionality and interactome of timp-1. Trends in cell biology, vol. 29(1), pp.6-19, 2019.

[3] T. Cong, H. Dan, W. Xiang.From pathogenesis of acne vulgaris to anti-acne agents. Archives of dermatological research,Vol.15,pp. (1-13), 2019.

[4] R. Lichtenberger, M. A. Simpson, C. Smith, . Genetic architecture of acne vulgaris. Journal of the European Academy of Dermatology and Venereology,Vol.31(12), pp.1978-1990, 2017.

[5] F. Suhr, Extracellular Matrix, Proteases and Physical Exercise. German Journal of Sports Medicine/Deutsche Zeitschrift fur Sportmedizin, vol.70,pp.(4), 2019.

[6] S. Pérez-García, M. Carrión, L. GutiérrezCañas, . Profile of Matrix-Remodeling Proteinases in Osteoarthritis: Impact of Fibronectin. Cells ,Vol. 9(1), pp.40, 2020.

[7] B. V. Gowri, P. L.Chandravathi, P. S. Sindhu . Correlation of skin changes with hormonal changes in polycystic ovarian syndrome: A 
cross-sectional study clinical study. Indian journal of dermatology.vol. 60(4), pp.419, 2015.

[8] L. Six, C. Grimm, S. Leodolter. A polymorphism in the matrix metalloproteinase1 gene promoter is associated with the prognosis of patients with ovarian cancer. Gynecologic oncology,Vol.100(3), pp.506510, 2006

[9] K. Bhate, and H. C. Williams. Epidemiology of acne vulgaris. British Journal of Dermatology,Vol. 168(3), pp.474-485, 2013. 